University of South Carolina

Scholar Commons

$1-1997$

\title{
Nondisclosure as a Contract Remedy: Explaining the Advance- notice Puzzle
}

John T. Addison

University of South Carolina - Columbia, ecceaddi@moore.sc.edu

John B. Chilton

Follow this and additional works at: https://scholarcommons.sc.edu/econ_facpub

Part of the Economics Commons

\section{Publication Info}

The Journal of Labor Economics, Volume 15, Issue 1, 1997, pages 143-164.

http://www.jstor.org/action/showPublication?journalCode=jlaboreconomics

(c) 1997 by The University of Chicago

This Article is brought to you by the Economics Department at Scholar Commons. It has been accepted for inclusion in Faculty Publications by an authorized administrator of Scholar Commons. For more information, please contact digres@mailbox.sc.edu. 


\title{
Nondisclosure as a Contract Remedy: Explaining the Advance-Notice Puzzle
}

\author{
John T. Addison, University of Hull and University of \\ South Carolina
}

John B. Chilton, University of South Carolina

Prior theoretical work predicts an underprovision of advance-notice contracts stemming from their enforcement costs. In the present model, it is rather the fundamental inability of workers to alienate their right to quit taken in conjunction with parameters central to job separation decisions that jointly determine the mix of notice and no-notice contracts observed in equilibrium. Not all equilibrium contracts are efficient, but there is no underprovision of notice. Mandating notice cannot improve on joint value and indeed may reduce it. Furthermore, although a mandate can be merely redistributive, there are cases in which it harms all parties.

\section{Introduction}

Empirical evidence suggests that workers who receive advance notice of impending job loss have significantly lower jobless duration than their nonnotified counterparts (for a tabular survey of the literature, see Addison and Portugal [1992]). The shorter spells of unemployment of notified workers are accounted for almost entirely by job finding during the notice interval, part of which takes the form of early quits (Ehrenberg and Jakubson 1989). Such "premature" quits, and other forms of worker exit behavior, presumably play a part in explaining why notice is not freely given. Indeed, less than $15 \%$ of displaced workers receive formal written notice (Addison and Blackburn 1994). If notice is so valuable to workers,

[Journal of Labor Economics, 1997, vol. 15, no. 1, pt. 1]

(C) 1997 by The University of Chicago. All rights reserved.

0734-306X/97/1501-0006\$01.50 
the puzzle is why we do not observe more contractual arrangements in which workers pay for the right to be notified via lower wages.

Previous theoretical work rests on a contractual commitment or enforcement failure attributed to notice contracts (Deere and Wiggins 1988; Kuhn 1992). In this view, a firm may very well want to guarantee its workers advance notice, but most firms cannot do so because they lack the means to enforce that promise. In particular, most firms do not promise notice because their workers foresee that they would (subsequently) renege to avoid the damage of premature quits. The firm commitmentfailure models thus use the presence of circumstances likely to facilitate self-enforcement (e.g., a large multiplant firm with a reputation to maintain, or a union which would economize on worker litigation costs) to predict whether a firm adopts notice. The presumption of these models is that a government mandate to give notice simply enforces a commitment not to engage in opportunistic behavior that firms are willing but may be unable to achieve on their own.

In this article, we embrace the reverse case and argue that the commitment problem applies to workers and not firms who can freely choose to commit to provide advance notice. ${ }^{1}$ We show that there exist conditions in which a firm would find a no-notice contract superior to an advancenotice contract and other conditions in which the reverse is true. Our model thus addresses both the frequency of voluntary notice agreements and employer opposition to mandated notice. There are three central results of our analysis. First, where the notice mandate binds, thereby harming the firm, there exist some circumstances in which the worker benefits and others where the worker loses. Second, should the mandate benefit workers, it is never possible for their gains to exceed the losses incurred by firms. Finally, there are conditions under which a firm voluntarily adopts notice even though there exist alternative no-notice contracts with the property that the gains to workers would exceed the loss to the firm, resulting in an overprovision of notice.

The key to understanding these results is that workers make their quit decisions without regard to the costs imposed on firms. For the firm, providing less information is a low-cost means of dealing with this moral

${ }^{1}$ Although it may explain why some firms do not offer advance notice, our position is that in many cases the cost of enforcing notice contracts is not the overriding issue. Most plant closures are not associated with bankruptcy or with the closure of the firm. For this reason workers can reasonably anticipate that should the firm break a promise to give advance notice it would have something to lose, either in the courts or by way of loss of reputation. Nor is it clear that there need be much ambiguity about what constitutes a violation; that is, noncompliance should be relatively easy for (current and future) participants and third parties to confirm. 
hazard on the part of workers. Take as the comparator the best available no-notice contract for the firm. Adding notice would increase the quit rate at the given wage, thereby decreasing the profit of the firm. We can infer that, because the information has an influence on the quit decision, the worker gains. To undo the adverse effect that information has on quits, the firm could of course raise the wage, but this response also yields lower profits than the original no-notice contract.

Another possibility is to provide notice and cut wages. Suppose that without this wage cut the gain to workers from notice exceeds the loss to the firm. The firm would now voluntarily furnish notice because there must exist a wage cut that would compensate it. If, however, the gain to workers does not exceed the loss to the firm, we have the conditions necessary to lead to the adoption of a no-notice contract. Surprisingly, these conditions are not sufficient. As was noted earlier, there exist cases in which the firm would still voluntarily offer a notice contract. This particular result is due to a monopsony effect: giving notice lowers the supply elasticity of labor retained and may create the incentive for the firm to trim wages. Perfectly analogous to conventional monopsony analysis, this notice contract is inefficient in the sense that there exist alternative contracts under which the winners could notionally compensate the losers.

The model is presented in the next section. Contracts yielding efficient retention are developed in Section III. Equilibrium is the subject of Section IV, leading to an evaluation of the consequences of a mandate in Section V. Robustness of the results with respect to bargaining power and contract flexibility is considered in Section VI, while the empirical content of the model is addressed in Section VII. Section VIII concludes.

\section{The Model}

There are two players, the firm and the worker. For simplicity, future cash flows are not discounted, and both the firm and the worker are assumed to be risk neutral. Players are equally ignorant at the outset, sharing common knowledge of the structure and parameters of the game $(\underline{u}, v, p, r, \omega)$, defined below. Bargaining is also of the simplest kind. The firm makes a take-it-or-leave-it contract offer that the worker can either accept or reject. ${ }^{2}$ Rejection terminates the game, yielding the firm a payoff of zero and the worker his reservation utility $\underline{u}>0$, where the latter is taken to be the market value of alternative employment. ${ }^{3}$

${ }^{2}$ The case in which the worker makes the offer is considered in Sec. VI.

${ }^{3}$ A positive opportunity cost for the firm could be easily introduced. In this case, in addition to its potential for distorting quits, mandated notice can be shown to lead to an inefficiently low level of employment. 
Immediately following acceptance of its offer, the firm privately learns whether it is to be permanent $(\mathrm{P})$ or temporary $(\mathrm{T})$ : the state is $\mathrm{P}$ with probability $p \in[0,1]$. The game then enters a 2 -period phase of real activity (either in production within the firm or in employment outside it, or in unemployment) after which the game ends. The value of the worker's marginal product is $v>0$ in each period the worker remains with the firm.

For the worker who has accepted a contract, outside offers paying $\omega$ $>0$ per period arrive just prior to the start of each period. The probability of receiving an outside offer just prior to any period is $r \in[0,1]$. Any outside offer that arrives prior to the first period, a first-period outside offer, is assumed for simplicity to be for a 2-period term of employment. A second-period outside offer is for 1 period of employment. The worker cannot hold on to outside offers. To take an outside offer the worker must immediately quit. Accordingly, the worker's tenure with the firm will be 0,1 , or 2 periods. The worker is with the firm for 0 periods if he or she quits at the start of the first period to accept an outside offer. The employment relation may end after 1 period either because the worker quits at the start of the second period or because the firm is temporary. The worker's tenure is 2 periods if the firm is permanent and he or she does not quit.

With slavery outlawed, a contract can bind a worker to the firm only by providing the incentive to stay. The worker will simply quit if he has an outside offer that is more attractive than staying with the firm. The incentives the firm can provide are a set of ordered pairs $(x, w) . x \in\{\mathrm{AN}$, $\mathrm{NN}$, where AN denotes an advance-notice contract and $\mathrm{NN}$ a no-notice contract. The AN contract is a binding commitment by the firm to inform the worker immediately if the state is T. The worker is informed in sufficient time to accept any outside offer of employment. The term $w$ is the contract wage, the per-period wage offered by the firm as long as the worker stays with the firm and the plant has not closed. Notice that any equilibrium contract must have the feature that $v-w$, the firm's profit in any period, be nonnegative. Thus, once a contract has been accepted, the firm will prefer that it be perceived to be permanent because this will tend to discourage premature quits. The assumption that the firm can make binding commitments to provide notice is not redundant for precisely this reason.

Note that contracting costs do play a role in our explanation for nonotice contracts. A no-notice contract (at an adequate wage) is a particularly simple arrangement for retaining the worker in all states. As is shown in Section VI, if we allowed for more complex contingent contracts, the quit behavior under a no-notice contract could be replicated at the same expected cost by an advance-notice contract. One such advance-notice contract would make the wage contingent on the firm's type, paying 
more when the firm is temporary. Furthermore, any quit behavior obtained under an invariant-wage, advance-notice contract could be purchased at lower cost with a state-contingent wage contract. This latter possibility would enhance the appeal of advance-notice arrangements to firms. Because few workers report receiving formal notice of plant closure, however, we are led to conclude that there are transactions costs of writing and administering these more complex contracts. ${ }^{4}$ Alternatively, the firm promising notice could pay a high but noncontingent wage to bind the worker. But this is more costly to the firm unless it also extracts an up-front lump-sum payment from the worker. Such arrangements are rare. Up-front payments are circumscribed not only by liquidity constraints but also because they attract firms whose sole interest is to take the money and run.

\section{Quit Behavior and Joint-Value-Maximizing Contracts}

\section{A. Quit Rules}

The equilibrium of the game will be found in conventional backwardinduction fashion. Thus, as a prelude to determining that full equilibrium in Section IV, we begin with rational quit behavior under any given contract so as to determine the value of alternative contracts to the firm and the worker. Note at the outset that second-period quit behavior is trivial: the worker with an outside offer quits if and only if $w<\omega$. (We shall decide the situation of worker indifference, here and elsewhere, in favor of staying with the firm.)

Under an NN contract, the worker with a first-period outside offer is indifferent about quitting when

$$
2 \omega=w+p w+(1-p) r \omega .
$$

The value $2 \omega$ is the payoff to the worker from an outside offer of guaranteed employment for 2 periods at the outside wage $\omega$. The expected value to the worker of staying is $w+p w+(1-p) r \omega$ : employment at contract wage $w$ is assured for the first period, while in the second period the worker faces the risk of plant closure, which results either in employment at the lower outside wage (indifference implies $\omega<w$ ) or in unemploy-

\footnotetext{
${ }^{4}$ Backloaded compensation might also be used as an alternative to state-contingent wages. But this creates room for malfeasance. Imagine a continuous-time model in which the worker could quit at any time within the notice period. A worker who, during this interval, quits or is fired for slack performance has the incentive to claim that the firm fired him to avoid paying severance. The resulting ambiguity for third parties makes enforcement costly.
} 


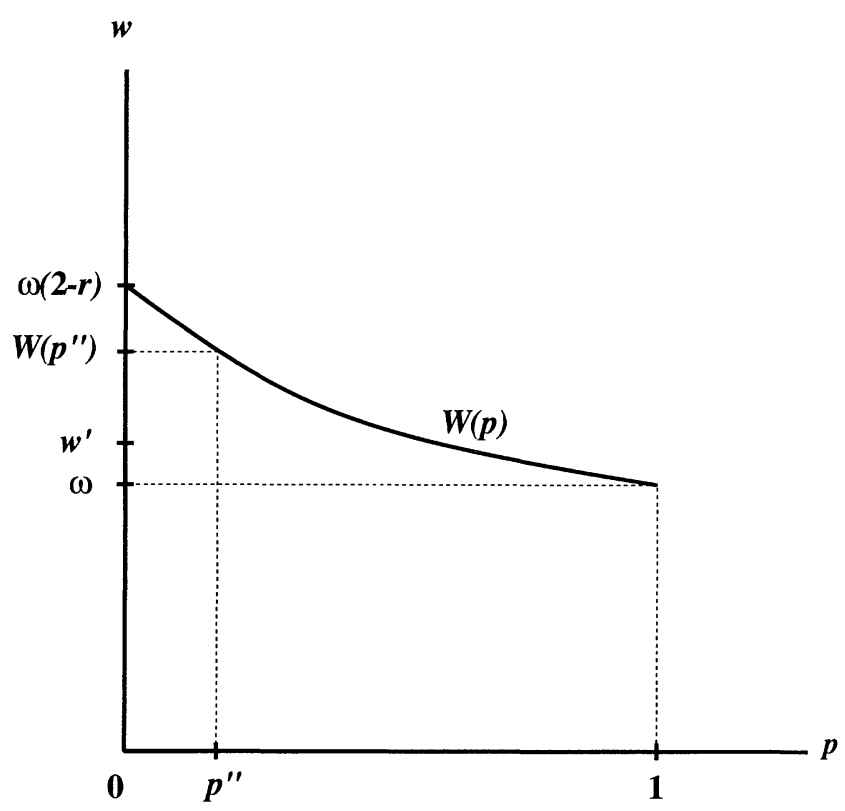

FIG. 1.-The $W(p)$ function

ment (the value of leisure is zero). Equation (1) defines a critical value of $w$, which is convenient to think of as a function of $p$ :

$$
W(p) \equiv \omega[2-(1-p) r] \div(1+p)
$$

Under a no-notice contract, the worker with a first-period outside offer will quit if the contract wage $w$ is less than $W(p)$. Evaluation of $W(\cdot)$ at $p=0$ and $p=1$ yields critical values under an AN contract when the firm is, respectively, $\mathrm{T}$ or $\mathrm{P}$. For future reference these values are

$$
W(0)=\omega(2-r)
$$

and

$$
W(1)=\omega
$$

The value $W(p)$ is monotonically decreasing in $p$, so $0<W(1) \leq W(p)$ $\leq W(0)$ for $0 \leq p \leq 1$. Figure 1 illustrates these properties of $W(p)$.

Contracts can be usefully classified into the quit rules they induce. There are three such categories: given a first-period outside offer, the worker's quit rule is to (1) always quit, (2) quit only if the firm is type 
Table 1

Expected Value of Contract Type NN

\begin{tabular}{ll}
\hline Contract Type & \multicolumn{1}{c}{ Expected Value } \\
\hline Always quit: & $J(\mathrm{NN}, w)=r 2 \omega+(1-r)[v+r \omega+(1-r) p v]$ \\
$w<W(1)$ & $u(\mathrm{NN}, w)=r 2 \omega+(1-r)[w+r w+(1-r) p w]$ \\
& $\pi(\mathrm{NN}, w)=r 0+(1-r)[(v-w)+(1-r) p(v-w)]$ \\
Always quit (first-period only): & $J(\mathrm{NN}, w)=r 2 \omega+(1-r)[v+p v+(1-p) r \omega]$ \\
$W(1) \leq w<W(p)$ & $u(\mathrm{NN}, w)=r 2 \omega+(1-r)[w+p w+(1-p) r w]$ \\
& $\pi(\mathrm{NN}, w)=r 0+(1-r)[(v-w)+p(v-w)]$ \\
Never quit: & $J(\mathrm{NN}, w)=v+p v+(1-p) r \omega$ \\
$w \geq W(p)$ & $u(\mathrm{NN}, w)=w+p w+(1-p) r \omega$ \\
& $\pi(\mathrm{NN}, w)=(v-w)+p(v-w)$ \\
\hline
\end{tabular}

$\mathrm{T}$ (which we shall term the contingent-quit rule), or (3) never quit. For example, referring to figure 1 , the contract $\left(\mathrm{AN}, w^{\prime}\right)$ is a contingent-quit contract because $W(1) \leq w^{\prime}<W(0)$. The worker with a first-period outside offer would quit if informed that the firm is type $\mathrm{T}$ but would stay if it is of type $\mathrm{P}$. Whether the contract $\left(\mathrm{NN}, w^{\prime}\right)$ achieves a neverquit or an always-quit allocation depends on $p$. In figure 1 , at $p=p^{\prime \prime}$, $W\left(p^{\prime \prime}\right)>w^{\prime}$. Under the contract $\left(\mathrm{NN}, w^{\prime}\right)$, therefore, if $p=p^{\prime \prime}$, a worker with a first-period offer would always leave the firm.

The following result is immediate:

LEMMA 1. Self-enforcing contracts. Any (NN, $w)$ contract with $w$ $<W(p)$ or any $(\mathrm{AN}, w)$ contract with $w<W(1)$ is an always-quit contract. Any $(\mathrm{AN}, w)$ contract with $W(1) \leq w<W(0)$ is a contingent-quit contract. Any (AN, $w)$ contract with $w \geq W(0)$, or $(\mathrm{NN}, w)$ contract with $w \geq W(p)$, is a never-quit contract. Further, if and only if $w<W(1)$, a second-period offer will result in a quit.

Given these quit rules, the value of alternative contracts can be determined. These values are presented in table 1 for $\mathrm{NN}$ contracts and in table 2 for AN contracts. We use $u(x, w)$ to signify the worker's payoff over the 2 periods from contract $(x, w)$, while $\pi(x, w)$ denotes the value of contract $(x, w)$ to the firm.

\section{B. Joint-Value-Maximizing Contracts}

Also included in tables 1 and 2 is the sum of $u(x, w)$ and $\pi(x, w)$, namely, the joint value of contract $(x, w)$, denoted by $J(x, w)$. We will subsequently use the joint-value maximum as a device in solving for the equilibrium contract offered by the firm. Here we begin that task, determining which contracts are joint-value maximizing.

The contract (AN, $v$ ) gives the worker all the value and all the information. It is therefore joint-value maximizing because the worker would always take the quit action that enhances joint value. Note the implication: permitting contracts that dictate the worker's course of action would 
Table 2

Expected Value of Contract Type AN

\begin{tabular}{ll}
\hline Contract Type & \multicolumn{1}{c}{ Expected Value } \\
\hline Always quit: & $J(\mathrm{AN}, w)=r 2 \omega+(1-r)[v+r \omega+(1-r) p v]$ \\
$w<W(1)$ & $u(\mathrm{AN}, w)=r 2 \omega+(1-r)[w+r \omega+(1-r) p w]$ \\
& $\pi(\mathrm{AN}, w)=r 0+(1-r)[(v-w)+(1-r) p(v-w)]$ \\
Contingent quit: & $J(\mathrm{AN}, w)=p 2 v+(1-p)[r 2 \omega+(1-r)(v+r \omega)]$ \\
$W(1) \leq w<W(0)$ & $u(\mathrm{AN}, w)=p 2 w+(1-p)[r 2 \omega+(1-r)(w+r \omega)]$ \\
& $\pi(\mathrm{AN}, w)=p 2(v-w)+(1-p)[r 0+(1-r)(v-w)]$ \\
Never quit: & $J(\mathrm{AN}, w)=p 2 v+(1-p)[v+r \omega]=v+p v+(1-p) r \omega$ \\
$w \geq W(0)$ & $u(\mathrm{AN}, w)=p 2 w+(1-p)[w+r \omega]=w+p w+(1-p) r \omega$ \\
& $\pi(\mathrm{AN}, w)=p 2(v-w)+(1-p)[v-w]=(v-w)+p(v-w)$ \\
\hline
\end{tabular}

create no further improvement in joint value. A corollary to lemma 1 characterizes the entire set of joint-value-maximizing (JVM) contracts:

COROLlaRY. JVM contracts. Always-quit contracts induce JVM first-period quit behavior if and only if $v \leq W(1)$. Contingent-quit contracts induce JVM first-period quit behavior if and only if $W(1) \leq v$ $\leq W(0)$. Never-quit contracts induce JVM first-period quit behavior if and only if $W(0) \leq v$. For $v \leq W(1)$, second-period quit behavior is JVM if and only if $w \leq W(1)$. For $v \geq W(1)$, second-period quit behavior under a contract $(x, w)$ is JVM if and only if $w \geq W(1)$. No other contracts are JVM with regard to quit behavior.

Proof. Lemma 1 can be employed to determine JVM quits. Specifically, take the joint value from any arbitrary sequence of events. The payoff to the worker from this same sequence of events is the same as the joint value other than in the replacement of $w$ by $v$ in the worker's payoff. In contrast to lemma 1 , the inequalities are weak because where there is indifference there is more than one class of JVM contracts. Q.E.D.

Together the corollary and lemma 1 imply that, despite the limitations on the set of feasible contracts, advance notice is not always necessary to achieve the joint-value maximum. Specifically, if $v \geq W(0)$, any contract with $w \geq W(0)$ will achieve the joint-value-maximizing never-quit allocation; if $v \leq W(1)$, any contract with $w \leq W(1)$ will achieve the jointvalue-maximizing always-quit allocation.

But might not firms refuse to offer advance-notice contracts when these are the only means of achieving joint-value maximization? In what follows, we shall evaluate equilibrium contracts and government mandated notice in terms of the criterion of joint value. We do find that there exist circumstances in which joint-value maximization is not achieved in equilibrium, but in each such instance an advance-notice contract (or its equivalent) is the culprit. It is immediate that a notice mandate can only reduce joint value.

\section{Equilibrium Contracts}

Since by assumption the firm makes a take-it-or-leave-it offer, the determination of equilibrium contracts reduces to the solution to the 
following optimization problem for the firm:

$$
\max _{x, w} \pi(x, w) \quad \text { subject to } u(x, w) \geq \underline{u} .
$$

The participation constraint, $u(x, w) \geq \underline{u}$, indicates that the worker will not accept a contract unless it is at least as valuable as the best alternative $\underline{u}$. If and only if $u(\mathrm{AN}, v) \geq \underline{u}$ will there exist contracts acceptable to the worker that yield the firm a nonnegative expected return. We adopt the convention that if no such contract exists then no contract is offered. Clearly, the firm and worker agree to a match if and only if it is efficient for the match to form. However, as we shall see, this does not imply that equilibrium contracts will necessarily create incentives for joint-valuemaximizing quit behavior.

Lemma 2 shows that certain contracts will never be offered. Note that these contracts are those found in the middle panel of table 1.

LEMMA 2. A contract $(\mathrm{NN}, w)$ with $W(1)<w<W(p)$ is never an equilibrium contract.

Proof. Comparing contracts $(\mathrm{NN}, w)$ and $(\mathrm{AN}, w)$, where $W(1)<w$ $<W(p)$, the worker with the (AN, w) contract will avoid the error of quitting in state $\mathrm{P}$. Thus, the worker strictly prefers the (AN, $w$ ) contract. In equilibrium $w \leq v$, so the ( $\mathrm{AN}, w)$ contract will be preferred by the firm as well. Q.E.D.

To streamline the presentation, we will concentrate on the special case in which $\underline{u}$ equals $u(\mathrm{AN}, 0)$ or, equivalently, $u(\mathrm{NN}, 0) .^{5}$ The general case is relegated to the appendix. The firm can narrow its choice of contract to three alternatives. These are (1) a least-cost always-quit contract, either $(\mathrm{AN}, 0)$ or $(\mathrm{NN}, 0)$; (2) the least-cost contingent-quit contract (AN, $\omega)$; and (3) the least-cost never-quit contract $(\mathrm{NN}, W(p))$. No other contract can be a solution to problem (2).

It is convenient to think of the firm as residual claimant, with the expected cost to the residual claimant of a contract $(x, w)$ equaling the worker's expected earnings $u(x, w)$. That is, the firm's payoff is just $\pi(x, w)=J(x, w)-u(x, w)$. We begin, then, by determining the worker's ranking of the three relevant alternatives.

The least-cost contingent-quit contract ( $\mathrm{AN}, \omega)$ pays a wage matching the outside wage $\omega$, leaving the worker indifferent between staying with a permanent firm and accepting an outside offer. The worker's earnings are $2 \omega$ when the firm is permanent or when the worker receives an outside offer (in any period). Otherwise - that is, when the firm is temporary

${ }^{5}$ An alternative interpretation is that the participation constraint is replaced by the constraint that the wage be nonnegative. 
and the worker does not find outside employment - the worker earns only $\omega$. Thus, the worker's expected earnings from $(\mathrm{AN}, \omega)$ are less than $2 \omega$. It is obvious that $u(\mathrm{NN}, 0)=u(\mathrm{AN}, 0)<u(\mathrm{AN}, \omega)$.

The least-cost means of always retaining the worker is to offer a nonotice contract at the wage $W(p)$ that leaves the worker indifferent between staying with the firm, not knowing its type, and accepting an outside offer. That wage as we have seen exceeds $\omega$ because, in comparison to a contingent-quit contract, a never-quit contract must compensate the worker for the error of staying with a firm that turns out to be temporary. The worker's indifference implies that his expected value from the leastcost never-quit contract is $2 \omega$, namely, the earnings possible from an outside offer.

To summarize, the worker's rankings are $u(\mathrm{NN}, W(p))=2 \omega>u(\mathrm{AN}$, $\omega)>u(\mathrm{AN}, 0)=u(\mathrm{NN}, 0)$. These results can be readily checked directly by referring to tables 1 and 2 .

Turning to the firm's rankings, consider first the case where only a contingent-quit contract maximizes $J$. The conventional wisdom suggests that, absent a mandate, most firms will provide too little information to workers with the result that retention rates are higher than they should be. But will the firm ever choose a never-quit contract, the contract that would result in fewer quits than is joint-value maximizing? No. The reasoning is straightforward. Compared to the leastcost efficient contract, the size of the pie, $J$, would be smaller and the worker is better off - the residual left to the firm would be smaller. Thus, contrary to the standard view, any departure from joint-value maximization will be in the direction of creating too many rather than too few quits. The firm will offer either the least-cost contingent-quit contract or a least-cost always-quit contract. Recall that the former is an advance-notice contract and that the provision of notice is irrelevant in the latter case.

In the case where only a never-quit contract is joint-value maximizing, the logical possibilities are that the firm provides either a never-quit contract or a contract that results in quits. The latter contracts shrink the size of the joint payoff, but since they give the worker less the firm's residual may actually increase. Note that where the firm offers a neverquit contract, the least-cost contract it offers is a no-notice contract.

The third case is transparent. If an always-quit contract maximizes joint value, the firm captures all the surplus by offering a least-cost alwaysquit contract.

We can summarize these results as follows:

PROPOSITION 1. Suppose there is no participation constraint. Equilibrium contracts either maximize joint value or create more quits than is joint-value maximizing. Any equilibrium contract that does not maximize joint value is (or is equivalent to) an advance-notice contract. 


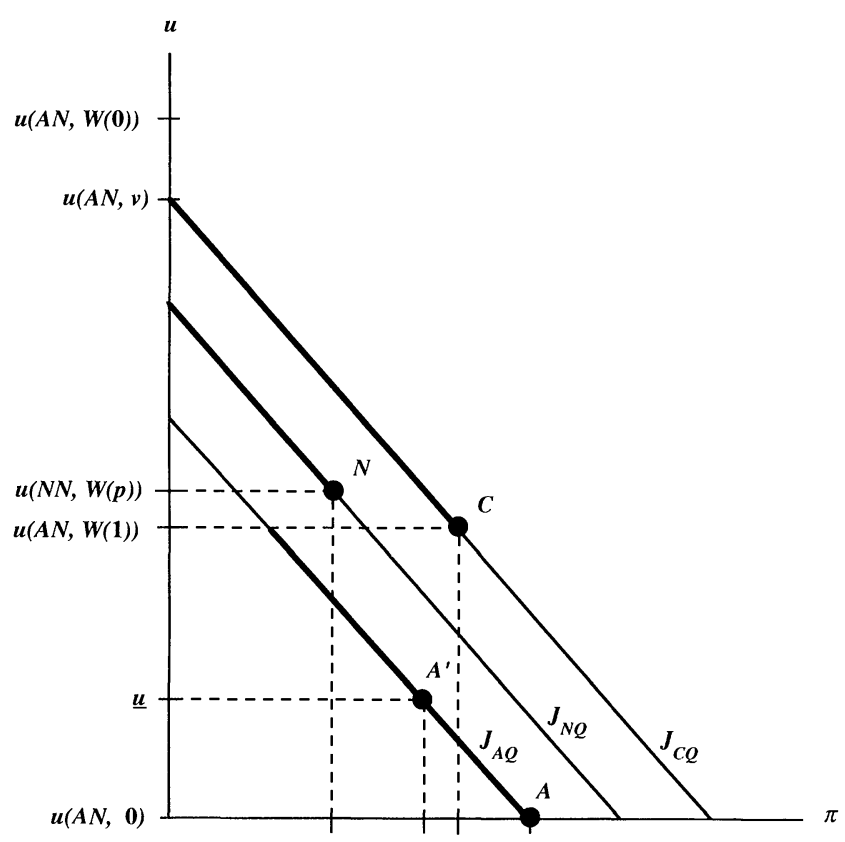

FIG. 2.-The case of $W(1)<v<W(0)$

Figure 2 gives a graphical presentation of the proposition for the case $W(1) \leq v<W(0)$ in which, from the corollary, a contingent-quit contract is necessary to maximize surplus. The three parallel lines are loci along which $J=\pi+u$ is constant. Along $J_{\mathrm{CQ}}$ the joint value equals that obtained if the worker follows contingent-quit behavior. The other two loci, $J_{\mathrm{NQ}}$ and $J_{\mathrm{AQ}}$, are defined in similar fashion-each lies below $J_{\mathrm{CQ}}$ in the case under consideration. The heavy segments indicate feasible allocations of $\pi$ and $u^{6}{ }^{6}$ To obtain contingent-quit behavior, an advance-notice contract paying between $W(1)$ and $W(0)$ is required. The heavy segment along $J_{\mathrm{CQ}}$ thus ends at allocation $C$, which corresponds to the contract (AN, W(1)). The worker with a first-period outside offer will quit even in the permanent state if the wage falls below $W(1)$. The resulting allocations belong to the heavy segment on $J_{\mathrm{AQ}}$. Never-quit behavior can be obtained with a no-notice contract paying at least $W(p)$. From the result that $u(\mathrm{NN}$, $W(p))>u(\mathrm{AN}, W(1))$, allocation $N$ in figure 2 must lie to the northwest of $C$ : as previously noted, the firm will not offer a contract that causes

${ }^{6}$ There are additional feasible outcomes not indicated (those from the middle panel of table 1), but we have already established via lemma 2 that these are Pareto-dominated by other contracts. 


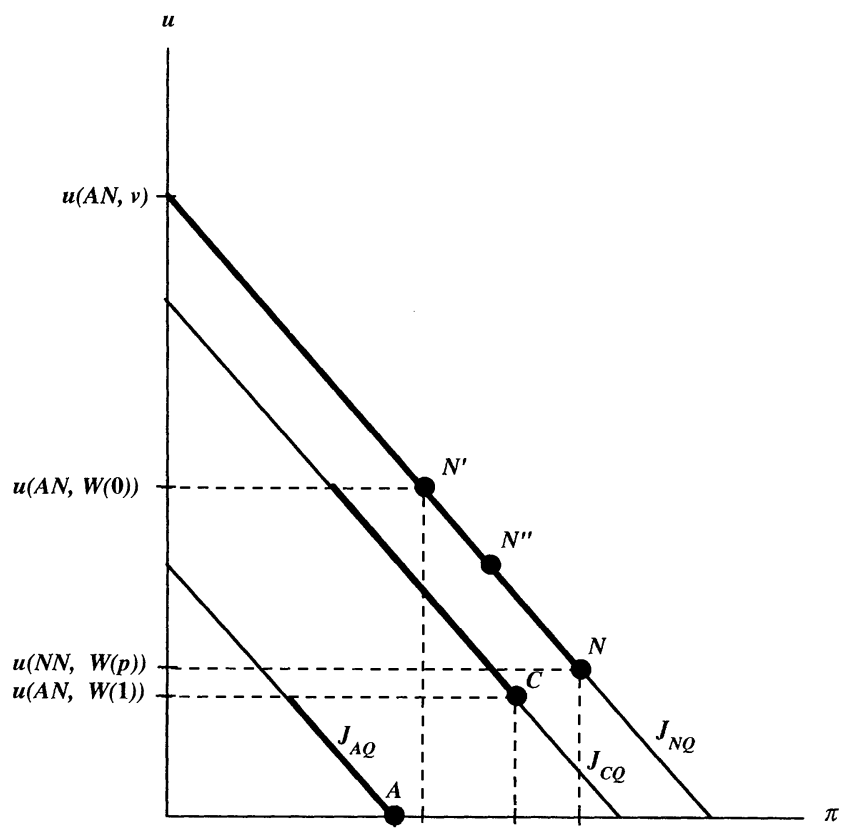

FIG. 3.-Equilibrium contracts when $W(0)<v$

fewer quits than is joint-value maximizing. However, as is illustrated in the figure, the firm may prefer the least-cost always-quit contract associated with allocation $A$ to its most preferred contingent-quit allocation at $C$. The equilibrium allocation is at $A$. Quits will be excessive. Joint surplus is not maximized because the increment in $J$ moving from $A$ to $C$ is not enough to compensate the firm for the increment to $u$ it must pay.

In figure 3 the locus $J_{\mathrm{NQ}}$ is farthest out, indicating that never-quit contracts maximize joint value. Again, point $N$ corresponds to the contract (NN, $W(p))$, while point $C$ corresponds to the least-cost contingentquit contract $(\mathrm{AN}, \omega)$. In the figure the firm prefers $N$ to $C$. If only advance-notice contracts were available to the firm, the least-cost neverquit contract would be $(\mathrm{AN}, W(0))$ associated with point $N^{\prime}$. If $N^{\prime}$ is to the northwest of $C$, then the firm would choose $C$. In other words, figure 3 demonstrates that the feasibility of no-notice contracts may make it attractive for firms to undo the distortion caused by the inability of the workers to commit to indentured servitude.

Further, the figure also illustrates the potential for monopsony inefficiency. In particular, it is possible that the point corresponding to the contract $(\mathrm{NN}, W(p))$ is not $N$, but rather $N^{\prime \prime}$, which is located to the northwest of $C$. In these circumstances, the firm will now select the 
contingent-quit contract $(\mathrm{AN}, \omega)$ rather than choose a joint-value-maximizing contract.

The effect of a participation constraint is to push the firm in the direction of joint-value maximization. For instance, in figure 2 at the reservation utility $\underline{u}^{\prime}$ the equilibrium becomes the joint-value-maximizing contract $C$ instead of the contract $A$. Figure 3 can likewise easily be deployed to show that a tightening of the participation constraint can convert the equilibrium from an advance-notice arrangement that does not maximize joint value to a no-notice equilibrium that does. The reader interested in the effect of the participation constraint is referred to the appendix.

\section{Mandates}

Consider the effects of a government mandate requiring advance notice. We will compare the pre- and postmandate equilibrium in terms of the joint value created and its distribution between the firm and the worker. Note we are not abrogating the notice conditions of an existing contract but, rather, comparing the equilibrium contracts across alternative regimes.

A notice mandate simply restricts the opportunity set of the firm in problem (2). It cannot therefore make the firm better off. Under what conditions does a notice mandate have an effect on equilibrium? The notice mandate eliminates from the firm's opportunity set only those outcomes associated with the no-notice contracts offering $w \in[W(p)$, $W(1))$. Every other contract either is an advance-notice contract or, because the contract wage is such that information has no value to the worker, is equivalent to an advance-notice contract. ${ }^{7}$ All such no-notice contracts without an advance-notice equivalent are never-quit contracts. From proposition 1 (and, more generally, proposition A1), never-quit contracts are used only if they are joint-value maximizing. We therefore have:

PROPOSITION 2. Joint value in the unrestricted equilibrium is greater than or equal to joint value in the equilibrium under a notice mandate.

Not only is it impossible in this model for all parties to gain from a notice mandate, it is also impossible for the gains of the winners to exceed the losses of the losers.

When the mandate constraint is binding, a never-quit contract becomes less profitable: the wage has to be larger to provide the incentive not to quit when the firm is temporary. The always-quit and contingent-quit contract alternatives are unaffected by the mandate. Where the firm never-

${ }^{7}$ Refer back to tables 1 and 2. The always-quit panels are identical. Contingentquit contracts are advance-notice contracts. Further, the never-quit panels overlap for $w \geq W(p)$. 
theless continues to favor a never-quit contractual arrangement, the effect of the mandate is to benefit the worker at the expense of the firm. Joint value is unaffected. If, however, the firm's preference is changed in favor of a contingent-quit or always-quit arrangement, joint value declines as a result of excessive quits. Further, recall that the least-cost never-quit contract is preferred by the worker to the least-cost always-quit and contingent-quit contracts. It follows that there are two possibilities if the notice mandate alters the firm's choice of contracts: either the participation constraint was slack to begin with (i.e., in the premandate equilibrium), in which case the worker's utility is now less than heretofore, ${ }^{8}$ or the participation constraint was binding, leaving the worker's utility unchanged. These results are summarized in proposition 3 .

Proposition 3. Assume the notice mandate is binding. Never-quit contracts maximize joint value. The mandate lowers the value of the firm. The premandate equilibrium contract is a never-quit no-notice contract. The postmandate equilibrium contract is one of the following: (i) a neverquit contract that the worker prefers, or (ii) an always-quit or contingentquit contract that for the worker is either inferior to or as good as the premandate equilibrium contract.

Proposition 3 says that if the notice mandate has an effect, it is either purely redistributive with the gain to the worker equaling the loss to the firm or it harms the firm and possibly the worker. Figure 3 can be used to illustrate the latter case. Allocation $N$ is the unrestricted equilibrium allocation, which achieves joint-value-maximizing never-quit behavior with the no-notice contract $(\mathrm{NN}, W(p))$. If the firm is constrained to offer notice, its best never-quit contract is associated with allocation $N^{\prime}$. However, in the situation illustrated, that firm will choose the contingentquit allocation $C$ that is inferior to the unrestricted equilibrium allocation $N$ for both parties.

Finally, table 3 provides some examples where the notice mandate is binding and shows that possibilities in proposition 3 are nonempty. The parameter values used are $p=0.5, r=0.6, \omega=2$, and $v=3$. The maintained parameter values imply that $W(p)=2.267, W(0)=\omega(2-r)$ $=2.8, u(\mathrm{AN}, W(1))=3.84$, and $u(\mathrm{NN}, W(p))=2 \omega=4$. A maximum joint value of 5.1 is implied. The joint value under a contingent-quit AN contract is 5.04 .

In the table various values of $\underline{u}$ are considered, just three of which are amplified here, beginning with $\underline{u}=3.95$. In the absence of a mandate, the firm would choose a joint-value-maximizing never-quit NN contract: the value of the firm would be 1.1. We can then infer that the worker would earn a rent of .05 (that is, $5.1-3.95-1.1$ ). The largest value of

${ }^{8}$ And is the sole outcome for $\underline{u}=u(\mathrm{NN}, 0)$. 
Table 3

Adoption of Notice Contracts That Are Not Joint-Value Maximizing $(\mathrm{JVM}): W(0) \leq v$

Parameter Values: $p=0.5, r=0.6, \omega=W(1)=2, v=3$

Endogenous Values: $W(p)=2.267, W(0)=\omega(2-r)=2.8$, $u(\mathrm{AN}, W(1))=3.84, u(\mathrm{NN}, W(0))=2 \omega=4$

\begin{tabular}{lcccc}
\hline \multicolumn{5}{c}{ Largest Value of Firm: } \\
\cline { 2 - 5 } & $\begin{array}{c}\text { Under } \\
\text { Contracts }\end{array}$ & $\begin{array}{c}\text { Under AN } \\
\text { Contracts with } \\
w \geq W(1)\end{array}$ & $\begin{array}{c}\text { Under JVM } \\
\text { Contract } \\
\text { When Notice } \\
\text { Iith } w<W(1)\end{array}$ & $\begin{array}{c}\text { Under NN } \\
\text { Contracts } \\
\text { That Are JVM }\end{array}$ \\
\hline 3.00 & $1.32 * \dagger$ & 1.20 & .30 & 1.1 \\
3.50 & .82 & $1.20 * \dagger$ & .30 & 1.1 \\
3.95 & .27 & $1.09 \dagger$ & .30 & $1.1^{*}$ \\
4.00 & .32 & $1.04 \dagger$ & .30 & $1.1^{*}$ \\
4.50 & 0 & $.54 \dagger$ & .30 & $.30^{*}$ \\
4.75 & 0 & .29 & $.30 \dagger$ & $.10^{*} \dagger$ \\
5.00 & 0 & .04 & $.10^{*} \dagger$ & \\
\hline
\end{tabular}

* Equilibrium contract without notice mandate.

$\dagger$ Equilibrium contract with notice mandate.

the firm under an AN contract is 1.09 , but this contract is not joint-value maximizing. Since $\underline{u}=3.95>u(\mathrm{AN}, W(1))=3.84$ and this AN contract does not maximize joint value, we can infer that the worker will just obtain his reservation utility if notice is mandated. In this case, the mandate harms not only the firm but also the worker.

Next consider $\underline{u}=4.5$. Absent the mandate, the firm would choose a never-quit NN contract, thereby maximizing joint value: the value of the firm would be 0.6 . From this we can infer that the worker just earns his reservation utility $\underline{u}$ (since $5.1-4.5-0.6=0$ ). The largest value of the firm under an AN contract is .54 , but this contract does not maximize joint value. Given $\underline{u}=4.5>u(\mathrm{AN}, W(1))=3.84$, and that joint value is not maximized, we can infer that where notice is mandated the worker obtains just his reservation utility. Only the firm is harmed; for the worker, the wage is reduced by an amount that exactly offsets the value of notice.

Finally, for $\underline{u}=4.75$, the firm would again choose a joint-value-maximizing never-quit NN contract: the value of the firm would be 0.35 . From this we can infer that the worker would earn no rent $(5.1-4.75$ $-0.35=0$ ). The largest value of the firm under a joint-value-maximizing never-quit $\mathrm{AN}$ contract is 0.3 . This is also the equilibrium contract under the mandate. (Having lost NN contracts as a binding mechanism, the firm substitutes the higher wage never-quit contract $(A N, W(0))$.) Since the contract is joint-value maximizing, the worker's utility under this contract must be $5.1-0.3=4.8>4.75=\underline{u}$. Only the firm is harmed; the worker benefits. 


\section{Robustness}

In this section we examine the robustness of our results to changes in certain key assumptions and offer some further justification for them.

We have assumed a simple bargaining framework where the firm makes a take-it-or-leave-it offer. If instead the worker makes the offer, he or she will always capture all the potential joint value by demanding the contract $(\mathrm{AN}, v)$. Under this contract the worker would receive all the marginal product, and quit decisions would be on the basis of the worker's lifetime marginal product from staying with the firm vis-à-vis that from taking an outside offer. Joint value would always be maximized. Extending the model to include a constraint for the firm's participation moves the results back into line with those where the firm makes the offer. In particular, suppose that the joint-value-maximizing contract form is never-quit and that the firm must earn at least $\pi>\pi(\mathrm{AN}, W(0))$ to cover its fixed costs. The contract (AN, $v)$ is joint-value maximizing but would be unacceptable to the firm. If a mutually acceptable contract exists, it is either an efficient no-notice contract or a contract resulting in excessively low retention.

Return to the original bargaining framework, but now allow for lumpsum transfers. The firm could capture all of the potential surplus by in effect selling the firm to the worker-offering the contract (AN, v), always efficient by the corollary, in return for a lump-sum payment equal to the maximum joint value net of the worker's reservation utility $\underline{u}$. It will always be rational for the firm to offer an advance-notice contract that maximizes joint value. Therefore, departures from joint-value maximization (with or without the mandate) vanish when lump-sum transfers are permitted. Further, the notice mandate cannot be redistributive. The mandate is completely emasculated. But as noted in the introduction, such lump-sum payments from worker to firm, and similar forms of posting bond, are rare.

Next, suppose the contract wage can depend on whether the firm is permanent or temporary. Such contracts are described by the 3-tuple $\left(x, w_{\mathrm{P}}, w_{\mathrm{T}}\right)$, where $w_{\mathrm{P}}$ and $w_{\mathrm{T}}$ are state-contingent wages. (By definition, $w_{\mathrm{P}}=w_{\mathrm{T}}$ under a no-notice contract.) Contingent-quit contracts become less costly for the firm to implement. To deter quits in the permanent state requires $w_{\mathrm{P}}$ be at least equal to $\omega$ in the permanent state. But $w_{\mathrm{T}}$ can be set below $\omega$ if deterring quits in the temporary state is not a goal. The cost of a never-quit contract is not changed by the freedom to make wages contingent on the state of the firm. This is patently true when the participation constraint binds. But it is also true if the participation constraint is slack: the worker has to be made indifferent between quitting and not quitting, regardless of the contractual notice provisions. Thus, the worker must be guaranteed an expected utility of $2 \omega$ : this is the cost 
to the firm. The contract $(\mathrm{NN}, W(p), W(p))$ will meet this condition. So, too, will the contract $(\mathrm{AN}, \omega, W(0))$, where in contrast to the contingentquit discussion, the wage is now greater in the temporary state than in the permanent state. Unlike the basic model, it follows that every nonotice contract-now including the never-quit variety - can be duplicated by an advance-notice contract through an appropriate choice of $w_{\mathrm{P}}$ and $w_{\mathrm{T}}$.

Since any no-notice contract can be duplicated by a contract (AN, $w_{\mathrm{P}}$, $\left.w_{\mathrm{T}}\right)$ for appropriate choice of $w_{\mathrm{P}}$ and $w_{\mathrm{T}}$, the effect of state-contingent wage contracts is to emasculate a notice mandate. The firm can negotiate around its effects. Lazear (1990) makes a similar point. But also like Lazear we are skeptical of a model in which mandates have no real effects. Our view is that transactions costs largely preclude complex, state-contingent contracts. ${ }^{9}$

\section{Empirical Predictions}

What conditions-in terms of the underlying parameters of the model-make advance-notice contracts likely in equilibrium? Here we provide a brief description of the model's empirical content. ${ }^{10}$

It has been established that the parameter space can be partitioned into three nonintersecting regions corresponding to whether the always-quit contract $(\mathrm{NN}, 0)$, the contingent-quit contract $(\mathrm{AN}, \omega)$, or the neverquit contract $(\mathrm{NN}, W(p))$ characterizes equilibrium. The firm will be indifferent between the never-quit and the contingent-quit contract when

$$
(1+p) v-2 \omega+(1-p) r \omega=[2 p+(1-p)(1-r)](v-\omega) .
$$

Note in particular that, independent of $p$, condition (3) holds when $r$ $=\omega / v$. The firm is indifferent between the contingent-quit and the always-quit contract when

$$
[2 p+(1-p)(1-r)](v-\omega)=(1-r)(1+(1-r) p) v
$$

${ }^{9}$ Absence of state-contingent wage contracts need not be evidence of conventional transaction costs. In an environment in which the parties are asymmetrically informed at the outset, the choice of contract by the informed party has the potential to reveal private information. Achieving such separation typically requires contracts with state-contingent payments. But, if the information will also later be used to the informed party's detriment, separating contingent contracts are unlikely to occur. See Kuhn (1994) for an example of a model related to the context of plant closure and early quits.

${ }^{10}$ We have shown that a tighter participation constraint pushes the firm that would otherwise offer an always-quit contract in the direction of a contingent-quit contract. Further, if $\omega / v \geq 1$, then always-quit contracts will be the equilibrium arrangement. In what follows, therefore, it is assumed that $\underline{u}=u(\mathrm{NN}, 0)$ and $\omega / v<1$. 


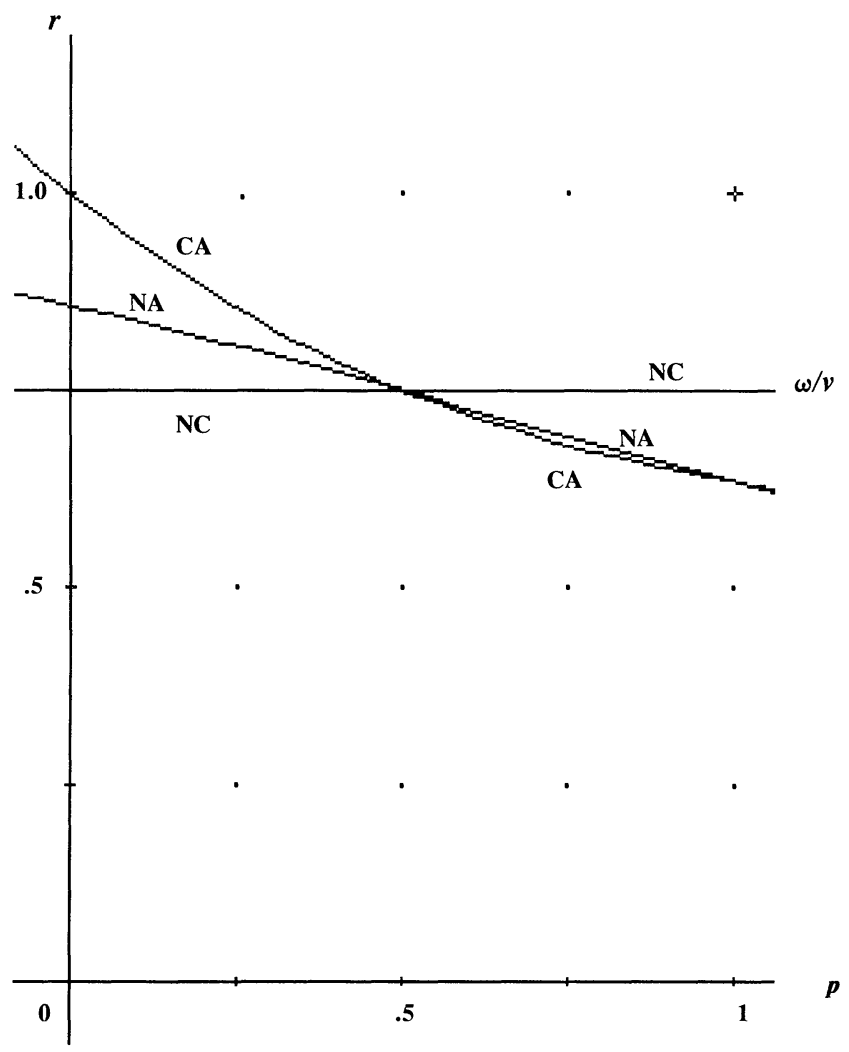

FIG. 4.-Equilibrium partition for $\omega / v=.75$

and between the never-quit and always-quit contracts when

$$
(1+p) v-2 \omega+(1-p) r \omega=(1-r)(1+(1-r) p) v .
$$

All three conditions of indifference are met simultaneously if and only if $p=.5$ and $r=\omega / v$. Both (4) and (5) imply an inverse relationship between $r$ and $p$. It can also be shown that at $p<.5$, the value of $r$ required to satisfy (4) is greater than that to satisfy (5), while the reverse is true for $p>.5$. It is further helpful to note that at $(r, p)=(1,0)$, condition (4) is satisfied.

Figure 4 illustrates these relationships using the value $\omega / v=.75$. The three contracts are the never-quit contract $\mathrm{N}$, the contingent-quit contract $\mathrm{C}$, and $\mathrm{A}$, denoting the always-quit contract. Along the locus $\mathrm{NC}$ the firm is indifferent between never-quit and contingent-quit contracts. The loci CA and NA are similarly defined mnemonically. For each locus the 
first (second) letter refers to which of the two contracts is preferred in the region above (below) the locus. In the intersection of the regions below CA and NA, the firm will offer the always-quit contract (NN, 0 ) or its equivalent $(A N, 0)$. In the region above $C A$ and below $N C$, the firm offers the contingent-quit contract $(A N, \omega)$. The equilibrium is the never-quit contract $(\mathrm{NN}, W(p))$ in the intersection of the regions above NA and NC.

Using figure 4, the empirical predictions of the model become transparent. Consider the region $p<.5$. As is evident from the figure, under this condition the firm will never offer the contingent-quit contract, the only interesting advance-notice contract. In the area to the right of $p=.5$ there emerges the wedge-shaped region bounded by $\mathrm{CA}$ and $\mathrm{NC}$ in which the firm offers advance notice to achieve the contingent-quit arrangement. For each value of $p>.5$, there is an interval of $r$ values within which the equilibrium is a contingent-quit advance-notice contract. The upper bound of this interval is always $r=\omega / v$. The lower bound falls with an increase in $p$. The lower the chance of plant closure, therefore, the more likely is a contingent-quit advance-notice contract.

Finally, consider the effect of increasing the outside offer $\omega$ relative to the value of marginal product $v$. It is easily confirmed that when $\omega / v$ $=1$ the three indifference loci collapse to $r=1$. This suggests that the contingent-quit region would shrink monotonically with an increase in $\omega / v$. Using numerical methods, we established this is indeed the case.

To summarize, we would expect contingent-quit advance-notice contracts where a small to moderate probability of plant closure is combined with a probability of an outside offer that is close to but below the ratio of the outside wage to the value of marginal product. The latter condition is least restrictive where the ratio of the outside wage to the value of marginal product is small. If these conditions are not met, we would expect to see no-notice arrangements, even if the cost of enforcing advance-notice contracts is low. This observation sharply differentiates our model from competing theories.

\section{Concluding Remarks}

Summers (1989) makes the case that mandated benefits can be justified if workers value the benefit they are receiving and are prepared to pay its cost through lower wages. Of course, there must be a market failure to explain the underprovision of the benefit in the first place; a common example is adverse selection in health insurance. By extension, there is a common perception that advance notice is also underprovided. As we have seen, the theoretical literature on advance notice starts from this perspective and finds a candidate for market failure in a commitment problem on the part of firms. On Kuhn's (1992) analysis, if all parties are at the outset equally uninformed of the firm's prospects, a notice 
mandate can benefit both the firm and the worker. The widespread opposition on the part of business in the debate leading up to WARN (the Worker Adjustment Retraining and Notification Act, Public Law 100379) suggests to us the straightforward possibility that voluntary notice may be feasible but is not necessarily sufficiently valued to justify its provision.

Indeed, we have shown that no-notice contracts can circumvent a potential market failure. They serve the productive purpose of binding the worker to the firm. There is a commitment problem, but it is on the part of the worker not the firm. The firm faced with a binding notice mandate will find in one of two alternatives the most profitable response, both of which are in sharp contrast to the Summers parable. The first possibility is to raise the wage so that the retention rate does not fall. The worker obtains a valuable benefit and the wage is increased, but there is no change in quits. The worker's gain is merely the firm's loss. The second alternative is to lower the wage, which is feasible precisely because the advance notice is valued. But this particular option exacerbates the true efficiency problem, namely, excessive quits. The worker pays for a valued benefit, yet at the same time a distortion is introduced by the form of payment. On the basis of our analysis, then, the case for mandated notice must rest on equity rather than efficiency grounds.

The overprovision of notice which we have identified can be interpreted as a consequence of a market failure, a missing market for jobs. If the firm could put a price on jobs via a lump-sum levy, the wage is freed to serve the role of achieving separation efficiency, and the amount of notice given will always be appropriate. All the surplus can be extracted by selling the firm to the workers, giving them all their marginal product along with full information. Of course, our basic result that a mandate can be of no benefit still stands. But now a mandate can do no harm either, since it places no constraint on the firm.

\section{Appendix}

\section{The Participation Constraint}

The results derived in the case $\underline{u}=u(\mathrm{AN}, 0)$ also hold in the more general formulation of the participation constraint. Consider the situation illustrated in figure 2 . In the figure, only contingent-quit contracts are joint-value maximizing, but at $\underline{u}=u(\mathrm{AN}, 0)$ the equilibrium contract is nevertheless the always-quit contract $(\mathrm{AN}, 0)$ because $\pi(\mathrm{AN}, 0)>\pi(\mathrm{AN}$, $W(1))$. This offers a rich set of possibilities illustrating the potential effects of the participation constraint. First, if $\underline{u} \leq u(\mathrm{AN}, 0), \underline{u}$ is so small that the participation constraint does not bind. Second, where $\underline{u}>u(\mathrm{AN}, 0)$ but $\underline{u}$ is sufficiently small, it will be the case that $\pi(\mathrm{AN}, w)>\pi(\mathrm{AN}, \omega)$, where $w$ satisfies $\underline{u}=u(\mathrm{AN}, w)$. The effect of the participation constraint will be to increase the equilibrium contract wage but still leave it in the 
range where the worker always quits. However, there is a critical value of $w$, call it $w^{*}$, where $\pi\left(\mathrm{AN}, w^{*}\right)=\pi(\mathrm{AN}, W(1))$ and $w^{*}<W(1)$. The third case, then, is $\underline{u} \geq u\left(\mathrm{AN}, w^{*}\right)$ and $\underline{u}<u(\mathrm{AN}, W(1))$ : the effect of the constraint is to cause the firm to switch to a JVM (joint-valuemaximizing) contingent-quit contract. This is the situation illustrated in figure 2, where the firm prefers allocation $C$ to $A^{\prime}$. Fourth, if $r \geq \underline{u}$ (AN, $W(1))$ and $\underline{u} \leq J(\mathrm{AN}, W(1))$, the equilibrium contract will be a contingentquit contract, and the firm extracts all the surplus. Finally, if $\underline{u}>J(\mathrm{AN}$, $W(1))$, there is no contract.

These results generalize to all cases:

PROPOSITION A1. The only respect, if any, in which the equilibrium contract does not maximize joint value is that there may be insufficient retention. In all departures from joint-value maximization, the equilibrium contract is (or is equivalent to) an advance-notice contract. Tightening the participation constraint by increasing $\underline{u}$ reduces the incidence of these contracts.

Proof. The possibilities can be partitioned into four cases. First, the participation constraint is not binding. Second, the participation constraint is binding but is slack for all JVM contracts. Third, the participation constraint is binding but is satisfied by some, though not all, JVM contracts. Fourth, the participation constraint is not satisfied by any JVM contract.

In the first case, the worker's utility in the equilibrium without the participation constraint is at least $\underline{u}$. The participation constraint has no effect on equilibrium. In the fourth case, the joint value of the match is negative. No match should or will occur.

If the participation constraint in the firm's problem (2) is binding and is violated for some JVM contracts - the third case - then the firm would offer the least-cost JVM contract consistent with participation.

This leaves the second case in which the participation constraint is binding in (2) but is slack for all JVM contracts. Absent the constraint, the firm would offer a contract inducing an excessive rate of quits in preference to the least-cost JVM contract, with the constraint that preference may be reversed. Because all JVM contracts satisfy the constraint, it has no effect on the profitability of the JVM contract alternative. The participation constraint is, however, binding, thereby reducing the profitability of contracts that do not maximize joint value. Q.E.D.

Using $p=0.5, r=0.4, \omega=2, v=3$, and $\underline{u}$ values of 3.1, 3.4, and 3.7, the interested reader can construct examples where the equilibrium is not JVM, where the participation constraint is slack but plays a role in ensuring the equilibrium is JVM, and where the participation constraint binds.

\section{References}

Addison, John T., and Blackburn, McKinley L. "The Worker Adjustment and Retraining Notification Act: Effects on Notice Provision." Industrial and Labor Relations Review 47 (July 1994): 650-62.

Addison, John T., and Portugal, Pedro. "Advance Notice and Unemploy- 
ment: New Evidence from the 1988 Displaced Worker Survey." Industrial and Labor Relations Review 45 (July 1992): 645-64.

Deere, Donald R., and Wiggins, Steven N. "Plant Closings, Advance Notice and Private Contractual Failure." Unpublished manuscript. Santa Barbara: University of California, Santa Barbara, December 1988. Ehrenberg, Ronald G., and Jakubson, George H. Advance Notice Provisions in Plant Closing Legislation. Kalamazoo, MI: W. E. Upjohn Institute for Employment Research, 1989.

Kuhn, Peter. "Mandatory Notice." Journal of Labor Economics 10 (April 1992): 117-37.

- "Nonrevelation in Employment Contracts." International Economic Review 35 (May 1994): 261-82.

Lazear, Edward P. "Job Security Provisions and Employment." Quarterly Journal of Economics 105 (August 1990): 699-726.

Summers, Lawrence H. "Some Simple Economics of Mandated Benefits." American Economic Review Papers and Proceedings 79 (March 1989): 177-83. 